\title{
Nurse risk takers during a crisis: The case of Liberia and the Ebola outbreak
}

During the largest outbreak of the Ebola virus in the history of the Mano River area in Sub-Saharan Africa, more than 40 nurses died from infection. A widespread saying noted that nurses were getting infected because of their "inattentive behavior" when performing procedures; however, this was not the case. The real problems were much more basic. Nurses had little training in the prevention and management of epidemics of communicable or transmissible infectious diseases of this magnitude. They also had no universal precaution protocols in place and nothing to remind them about safety measures when performing their daily duties. In addition, medical supplies and protective equipment were lacking.

\section{HOW DID NURSES IN LIBERIA BECOME BRAVE TO TAKE ON THE CHALLENGE OF CARING FOR PATIENTS WITH EBOLA?}

In March 2014, the Ministry of Health in Liberia, in collaboration with the World Health Organization (WHO), rolled out a protocol termed "Keep safe; keep serving" (simply put KSKS). This was followed by the provision of protective equipment by the People's Republic of China. In addition, the Liberian Nurses Association began training personnel while protective equipment was distributed to all facilities (public, private, and faith-based). Nurse risk takers took up the challenge and went back into their communities, clinics, health centers, hospitals, and the Ebola training units to provide quality nursing care.

\section{HOW DID THE VIRUS SPREAD?}

The epidemic spread quickly, with thousands of Liberians dying because of the fragile health system that planned reactively rather than proactively. The epidemic first

Correspondence: Shirley Gbalee Seckey- Fahnbulleh, C/O Liberian Nurses Association P.O. Box 1906 James A.A. Pierre Building, Carey Street 1000 Monrovia, 10 Liberia. Email: shirna1@yahoo.com started in the Northern part of the country about 100 miles from the capital city of Monrovia. But in just a few months, 12 other counties were affected.

It has been a year since the WHO announced on May 11, 2015, that Liberia was "Ebola-Free." Yet the issues nurses face here continue to be significant, and nurses everywhere are pressured to assume more and more risks in our global environment. As one author has argued, "Inherent in the role of today's nurse is the ability to make decisions, often with risk, at both individual and collective levels" (Wolf, 1994, 43). Indeed, all health care workers are facing greater risks as their practices become less routine and more uncontrollable (Westmorland, 1999; O’Byrne, 2008; McNeill, 2014; Kim, et al., 2015). Literature shows that many nurses are, in fact, willing to take risks that involve danger and "to make informed decisions regarding the probability of rewards and the consequences associated with failure" (Wolf, 1994, 43). But when these risks are assumed, nurses need the support and resources to do so.

Currently the system is not adequately prepared for any further outbreaks. Health care providers are still being exposed to dangers because of a lack of medical supplies. Indeed, a physician from one of the referral hospitals in Monrovia expressed his fear that they were running out of protective equipment. This problem is not unique to this facility but to those all across the country.

This shortage must be given immediate attention, because there remain pockets of infected cases today. Nurses are better trained now to respond, but without appropriate protective equipment, they again will be exposed to risk and thus will be unable to provide quality care to their patients in an environment that protects the nurses as well.

\section{WHAT IS THE WAY FORWARD?}

We must build a robust and resilient health system, where quality improvement is a key factor. It is important that private, government, and faith-based facilities be given minimum standards for operation that include continuous medical and nursing education, the availability of drugs 
and medical supplies, and the adherence to universal precautions at all times.

\section{CONCLUSION}

Nurses in Liberia are risk takers; they are not inattentive, despite the accusations widely spread during the Ebola outbreak. It takes bravery as well as education to do what they do. They comprise 85 percent of the health work force in Liberia; and they are educators and advocates as well as care givers. As such, they are an important link to health care in the country and deserve respect and protection by the Liberian government and all partners. They should have supplies available to help them provide safe and quality care to the Liberian people. Without nurses, the country will once again fall into despair when another unexpected outbreak occurs.
Shirley Gbalee Seckey- FAHNBULLAH

Academic Consortium Combating Ebola in Liberia Infection Prevention Control Department

\section{REFERENCES}

Kim, L., Lyder, C., McNeese-Smith, D., Leach, L., \& Needleman, J. (2015). Defining attributes of patient safety through a concept analysis. Journal of Advanced Nursing, 71 (11), 2490-2503.

McNeill, C. (2014). Risk: A multidisciplinary concept analysis. Nursing Forum, 49 (1), 11-17.

O'Byrne, P. (2008). The dissection of risk: a conceptual analysis. Nursing Inquiry, 15 (1), 30-39.

Westmorland, M. (1999). Risk taking: An antidote to diffidence. Canadian Journal of Occupational Therapy, 66, 214-219.

Wolfe, P. L. Risk taking: nursing's comfort zone. Holistic Nursing Practice, 8 (2), 43-50. 